\title{
Women awareness and satisfaction toward health services provided at family health centers
}

\author{
Hala Ragab Abd EL-Aaty ${ }^{1}$, Yosria El-sayed Hosein ${ }^{2}$, Soad Abd-Elhamed Sharkawy ${ }^{3}$, Naglaa Mohammed Amin ${ }^{4}$
}

1. B. Sc in Nursing, Minia University, Egypt.

2. Professor of Community Health Nursing Faculty of Nursing- Minia University.

3. Assist. Professor of Community Health Nursing Faculty of Nursing- Assiut University.

4. Lecturer in Community Health Nursing Faculty of Nursing, Minia University.

\begin{abstract}
Family health centers are the first gates to provide women with health services; health care services constitute a wide range of curative and preventive health services of particular importance to women's health. Aim of the study: to assess women's awareness and satisfaction toward health services provided at family health centers. Research design: a descriptive research design was used to conduct the study. Sample: a multistage random sample of 723 women was selected from four family health centers in Assiut city in the following villages (Zawia, Dronka, Menqbad, Bani Hussein villages). Data collection Tool: one tool was used in the study: part one included items related to demographic characteristics and personal history, part two: women's awareness about health services provided by family health centers and part three: women's satisfaction questionnaire about health services provided by family health centers. Results: more than half of the studied women $(58.9 \%)$ aged ranged between $18-<30$ years and aware with health services provided at family health centers. Regarding the studied women satisfaction of availability services provided at the family health centers near to two third of them satisfied with health services and there was no statistically significant relationship between demographic data of the studied women and their awareness with the health services provided at the family health centers except their age and reproduction for married participant with their awarenss.. Conclusion: more than half of studied women aware with health services provided at family health centers and near to third of them satisfied with health services. Recommendations: Primary health care programs related to health services should be developed to improve the awareness and satisfaction of Egyptians specifically for women and increases health education programs on how to improve health promotion and the use of health services.
\end{abstract}

Keywords: Awareness, Satisfaction, Health Services, Family Health Centers.

\section{Introduction}

Health services as primary care is the most frequently used in any health care system. The World Health Organization (WHO) defined that it is essential health care services made universal accessible to individuals and families in a community by means acceptable to all peoples. Health centers generally introduce health services in terms of primary care as preventive and curative services, mostly adapted to local needs (Radhi, 2016).

The mission of the Family Health centers is to improve the well-being of families by increasing public awareness and professional education and assuring access to a system of care that is family-centered and community-based. This system should include preventive, early detection, treatment, habilitative and rehabilitative services. The Family Health centers administer and coordinate programs and services concerned with health promotion and disease prevention for families, including women of childbearing age, mothers, infants, children and youth (Kuo et al., 2012).

In Egypt Community health centers (CHCs) provided primary health care to over 20 million patients in $2011,60 \%$ of whom are women and $25 \%$ of whom are women of childbearing age (Wood et al., 2013). Health centers play a central role in women's health, it is projected that health center capacity will virtually double by 2019 , and accordingly, the role of health centers in the provision of women's health care services can be expected to grow significantly (Neuhausen et al., 2012).

Health services provided by family health centers related to family medicine, internal medicine, pediatrics, obstetrics, or gynecology, that are furnished by physicians and where appropriate, physician assistants, nurse practitioners, and nurse-midwives Diagnostic, laboratory, and radiologic services , Preventive health services including: prenatal and

$P$ a g e | 158 perinatal care; appropriate cancer screening; well-child services; immunizations for vaccine-preventable diseases as may be appropriate for particular centers (Wood et al., 2014).

Woman satisfaction in the primary health care is a key marker for the quality of health care delivery and this internationally accepted factor needs to be studied repeatedly for smooth functioning of the health care systems. woman' satisfaction has long been considered as an important component when measuring health outcome and quality of care in both developed and developing countries and constitutes a significant indicator of the health care quality (Mohamed et al. 2015).

Community health nurse plays key roles and providing community health services in disease and injury prevention, disability alleviation and health promotion, as well as managing and providing care and follow-up across a broad range of settings. Community health nursing promotes and protects the health of populations through a combination of knowledge derived from nursing, social and public health sciences (WHO, 2017).

\section{Significance of the Study}

The Egyptian Health system started to face many difficulties due to the increase in the population, the emergence of new health problems, the economic crises and the problems of the gap in the system itself. Regarding the main health indicators for Egypt, these can include maternal and child health indicators, chronic disease indicators and infectious diseases indicators which illustrate the main burden of disease in Egypt (Ebeid, 2016). Internationally a multistate study done by Robert 2016) found that health center patients had 24\% lower spending as compared to non-health center patients across all services. Health Center Program is effective to provide high quality and comprehensive primary

Hala R., et al 
health care services in underserved communities (Nocon et al., 2016).

Health centers improve health outcomes by emphasizing the care management of patients with multiple health care needs and the use of key quality improvement practices, including health information technology. Health centers reduce costs to health systems; the health center model of care has been shown to reduce the use of more costly providers of care, such as emergency departments and hospitals (Laiteerapong et al., 2014).

Health improvement strategies with a focus on increasing mothers' knowledge and awareness about the services given, the benefits of these services (Coast et al., 2014), complications related to pregnancy and delivery should be designed and implemented. Skilled attendants at the Health Post level should be trained and assigned to provide home delivery (ten Hoope et al., 2014).

\section{Aim of the Study:}

The current study aimed to assess women awareness and satisfaction toward health services provided at family health centers.

\section{Research Questions:}

1) What is the level of women awareness toward health services provided at family health centers?

2) What is the women satisfaction concerning the health care services provided at family health center?

3) Is there a relationship between the demographic characteristics and the level of women awareness, and their satisfaction with the health services provided by family health centers?

\section{Subjects and Methods \\ Study design:-}

A descriptive research design was used for the current study.

\section{Setting:-}

The study was conducted at Family health centers (FHC) at Assiut city. Assiut city includes (9) family health centers (4) centers were selected randomly that providing numerous services such as providing obligatory vaccination, family planning services, and antenatal care and post natal care including women attending FHC for family planning and antenatal care. In the following villages (Zawia village, Dronka village, Menqbad village, Bani Hussein village) .

The Menqbad Family Health Center is located in the village of Menqbad in Assiut. serving northeast of Assiut city and has a population of around 47,000 inhabitants. Zawia FHC is located in the village of Zawiya in Assiut. Located next to the gas station cooperation, serves the south-western city of Assiut and has a population of around 34,200 inhabitants, Dronka FHC is located in the village of Dronka in the city of Assiut. Located next to the local unit in Dronka, and serves the south-western city of Assiut with has a population of around 46,000 inhabitants and finally Bani Hussein, located in the village of Bani Hussein in the city of Assiut. Located near the police station Bani Hussein, and serves the northeast of the city of Assiut, with has a population of around 16,000 inhabitants. This (4) Family Health Center is one of the villages of Assiut center at Assiut city.

\section{Subject:}

A multistage random sample was used in this study. Assiut city includes (9) family health centers (4) centers were selected randomly. The total number of attendance of family health centers in the last six months in 2017 was (65153) attendance. by using software EPI /info, version 3, 3 with 99 $\%$ confidence interval $(\mathrm{CI})$. The estimated sample size found to be ( 657 ) attendance and increased $10 \%$ to be ( 723 ) attendance to avoid drop-out and refuse. Divided into (10\%) from each center as follows:

Table (1):- Sample size related to each family health center:

\begin{tabular}{|l|c|c|}
\hline \multicolumn{1}{|c|}{ Name of family health Centers } & $\begin{array}{c}\text { Actual number } \\
\text { of attendance }\end{array}$ & $\begin{array}{c}\text { Sample } \\
\text { size }\end{array}$ \\
\hline Family health center in the village of Zawia. & 24577 & 260 \\
\hline Family health center Dronka. & 16560 & 190 \\
\hline Family health center in the village of Menqbad. & 17336 & 203 \\
\hline Family health center in the village of Bani Hussein. & 6680 & 70 \\
\hline Total number & 65153 & 723 \\
\hline
\end{tabular}

Multistage random sample of the woman participated according to inclusion criteria for 6 months from October 2018 to March 2019.

\section{Inclusion criteria:}

1 - Women 18 years and above.

2- Having at least one experience in dealing with the primary care facility, and willing to participate in the study.

\section{Data Collection Tools}

Data was collected through the utilization of structured interviewing questionnaire which was developed \& translated into Arabic language by the investigators after extensive review of literature. it consisted from three parts as follows:

\section{Part (1): Personal Data Questionnaire:-}

Covers the data related to general characteristics (age, sex, residence, marital status, occupation, and level of education, no. of children.....etc.

\section{Part (2): The women awareness about health services} (Assessment Tool Questionnaire):

The women awareness about health services (Assessment tool questionnaire) was developed to assess woman awareness about health services Provided by family health centers such as, The type of services you receive from the centers, Pregnant care services, Pre-marital screening services, Pharmacy Services, Laboratory Services, Family Medicine Files, does your family have a folder in the family health center, referral Services, , Family planning services, Health education services, Follow - up of children services, Medical examination services........etc. It was adapted from (Ebeid, 2016).

Scoring system: The scoring system for the collected data regarding women's awareness was score (2) degree was given for each (yes) answer and a score (1) degree was given for (No) answer. The total score of awareness was (180) degree. The score was calculated by summing up and converted into a percentage score as the following.

- *Good: if the percent score is $50 \%$ or more.

- *Poor: if scored less than $50 \%$. 
Part (3): The women Satisfaction about health services (Assessment Tool Questionnaire):

Was developed by (Dyer et al., 2016) Likert Scale checklist to assess women Satisfaction with acceptance of health services provided by family health centers, It consisted of (30) items such as Health services provided at the family health center are acceptable, meets your family needs, and good quality, The method of medical examination in the clinics of the center, The center buildings, Waiting places are ready, Cleanliness of the place, Dental services, Emergency services in the center, Skilled center' physicians, System of recording and extracting files...........etc.

Scoring system: the scoring for women's satisfaction was (2) degree for satisfactory response, (1) degree for unsatisfactory, and zero degrees for I do not know. The score was calculated by summing up and converted into a percentage score as follows. If Responses of $(50 \%)$ or more indicate that the woman is satisfied with the acceptance of the health services provided by the family health center. If Responses less than $(50 \%)$ indicate unsatisfied women and un-acceptance of the health services provided by the family health center.

\section{Content Validity}

The content validity of the data collection tools was determined the tools were submitted to five experts in community health nursing to test their validity. The tools were examined for content coverage, the sequence of items, clarity, relevance, applicability, wording, length, format, and overall appearance. Based on experts comments and recommendations; minor modifications had been made such as rephrasing and rearrangements of some sentences.

\section{Reliability}

The tool was tested for internal reliability (reliability referred to the consistency of measurement and was frequently assessed using the test-retest reliability method). To achieve the reliability of the questionnaire, the instrument was designed with great care matching questions with objectives for the study. Tools reliability was done to identify the extent of tools items were measurable with the study concept and its correlation with apiece other. Cronbach's alpha reliability was 0.757 it used to check the stability of the internal consistency of the instrument.

\section{Ethical Consideration}

Approval was sought from the Provincial and district ethical committee before undertaking the research. The purpose of the study was explained to all participants by the investigator. The participant had ethical rights to agree or refuse to participate in the study. Oral consent was obtained from every participant. Every participant was informed that the information and data obtained was confidential and used only for the study.

\section{Study Procedure}

Official permissions were obtained from the Research Ethical Committee of Faculty of Nursing, as well as Assiut directorate of health, then of the previously selected family health centers. This letter included a brief explanation of the objectives of the study and permission was requested from each Manager to carry out the study.

After extensive review of relevant national and international literature, tool of data collections was developed by the investigator in 2018. Prior to data collection, tool for data collection translated from English to Arabic version language and transverse translation again from Arabic to English.

The data collection study was carried out from the beginning of October 2018 and finished at March 2019. The researchers attended in family health center to collect data with average of three days per week to collect data, at official work time by using the structured interview questionnaire sheet. At the beginning of interview the researchers greeted each woman, utilizing proper channel of communication and explained the purpose of the study and taken their oral consent before being involved in the study after explanation of the nature of the study its benefits and there are no risks or cost in participation, and there are voluntary participation and confidentiality of each subject who agree to participate to fill the questionnaire.

The questionnaire sheet was filed by investigators during 15 - 20 minute or more for each woman and about 10 12 woman in every day depending on the response of each women. Finally the investigators thanked the participants for their cooperation.

\section{Results}

Table 1: Distribution of demographic data among studied women at family health centers $(\mathrm{n}=723)$

\begin{tabular}{|l|c|c|}
\hline \multirow{2}{*}{\multicolumn{1}{|c|}{ Items }} & \multicolumn{2}{c|}{ Studied women } \\
\cline { 2 - 3 } Age / years & & No. \\
\hline $18<30$ & & \\
\hline $30<42$ & 426 & 58.9 \\
\hline $42<54$ & 231 & 32.0 \\
\hline 54 and more & 54 & 7.5 \\
\hline Mean \pm SD & 12 & 1.6 \\
\hline Educational level & \multicolumn{2}{|c|}{$29.84 \pm 8.485$ years } \\
\hline Illiterate & \multicolumn{2}{|c|}{} \\
\hline Basic education & 252 & 34.8 \\
\hline Secondary & 237 & 32.8 \\
\hline University education & 138 & 19.1 \\
\hline Marital status & 96 & 13.3 \\
\hline Single & \multicolumn{2}{|c|}{} \\
\hline Married & 46 & 6.4 \\
\hline Divorced & 644 & 3.1 \\
\hline Widow & 23 & 1.4 \\
\hline Occupation status & 10 & \\
\hline
\end{tabular}




\begin{tabular}{|l|c|c|}
\hline \multicolumn{1}{|c|}{ Items } & \multicolumn{2}{c|}{ Studied women } \\
\cline { 2 - 3 } & No. & \multicolumn{1}{c|}{} \\
\hline Working & 47 & 6.5 \\
\hline Housewife & 676 & \\
\hline $\begin{array}{l}\text { Reproduction status for married participants } \\
\mathbf{n}=677\end{array}$ & & 83.5 \\
\hline Have children & 592 & 12.6 \\
\hline Do not have children & 85 & \\
\hline
\end{tabular}

Table 1: Showed that more than half of the study sample $(58.9 \%)$ were in age group $18-<30$ years, while the least percentage was (1.7\%) in the age group 54 and more years with age mean and standard deviation $29.8 \pm 8.48$ years. As regard the level of education the more than one third (34.8\%) of the women were illiterate, and the minority of them (13.3\%) had university education. As regards occupation status the highest percentage $(93.5 \%)$ was housewives while the lowest percentage $(6.5 \%)$ of them was working. Lastly the marital status the highest percentages were married (89.1\%) while the lowest percentages were widow (1.4\%). As regard the reproduction status for married women the highest percentage (87.4\%) have children while the lowest percentage (12.6\%) was do not have children.

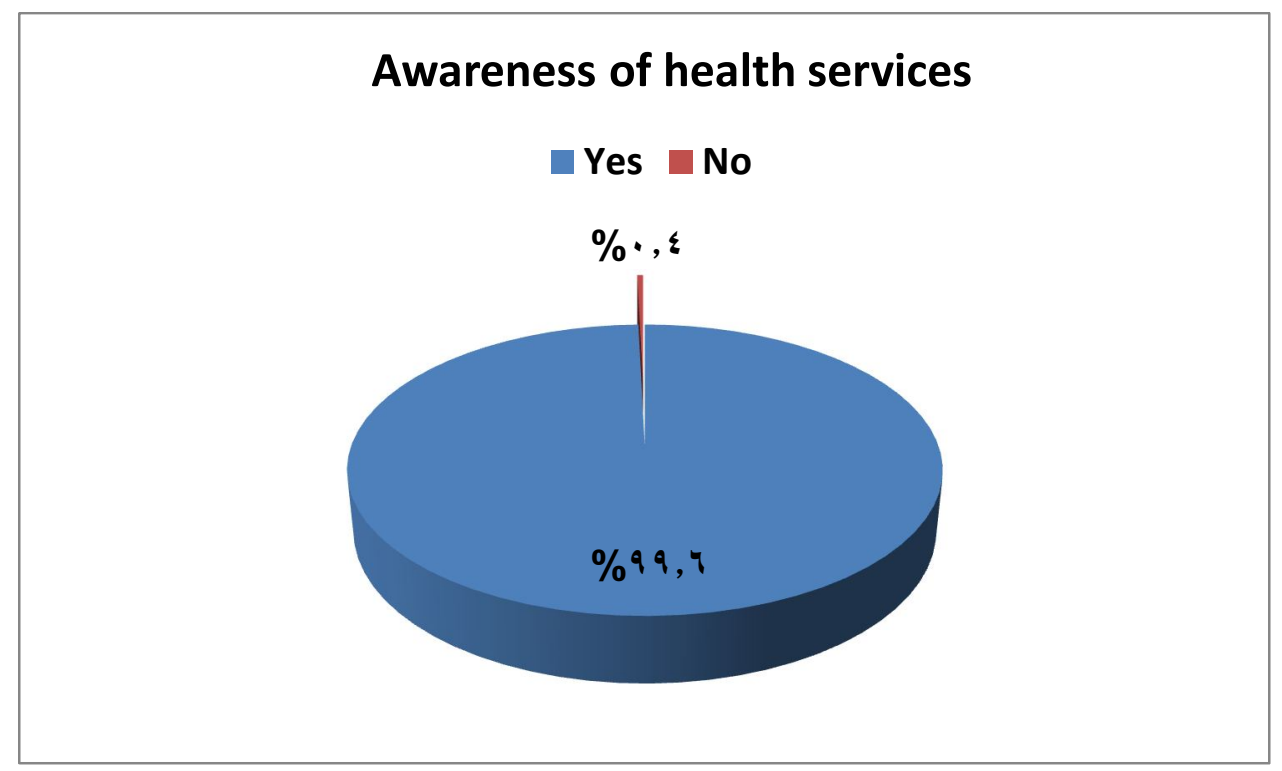

Figure (1) Percentage distribution of awareness among studied women regarding health services provided at family health centers.

Figure 1: As regarding the awareness of health services provided at family health centers it was shows that $99.6 \%$ of the studied sample aware about this health services.

Table 2: Distribution of studied women awareness related to the health services provided by the family health center ( $\mathrm{n}=723$ )

\begin{tabular}{|c|c|c|c|c|c|}
\hline & \multirow{2}{*}{ Family health center services } & \multicolumn{2}{|c|}{$\begin{array}{c}\text { studied women } \\
\text { Yes. } \\
\end{array}$} & \multicolumn{2}{|c|}{$\begin{array}{c}\text { studied women } \\
\text { No. }\end{array}$} \\
\hline & & No. & $\%$ & No. & $\%$ \\
\hline- & Follow - up of children. & 653 & 90.3 & 70 & 9.7 \\
\hline- & Compulsory vaccinations for children. & 670 & 92.7 & 53 & 7.3 \\
\hline- & Examination of the thyroid gland for the newborn. & 624 & 86.3 & 99 & 13.7 \\
\hline - & Pre-marital examination. & 54 & 7.5 & 669 & 92.5 \\
\hline - & Family planning. & 649 & 89.8 & 74 & 10.2 \\
\hline - & Ante natal care. & 701 & 97.0 & 22 & 3.0 \\
\hline- & Tetanus vaccinations for pregnant women. & 682 & 94.3 & 41 & 5.7 \\
\hline- & Medical examination. & 456 & 63.1 & 267 & 36.9 \\
\hline- & Laboratory services. & 595 & 82.3 & 128 & 17.7 \\
\hline- & X - Ray services. & 168 & 23.2 & 555 & 76.8 \\
\hline- & Pharmaceutical services. & 575 & 79.5 & 148 & 20.5 \\
\hline- & Emergency care. & 479 & 66.3 & 244 & 33.7 \\
\hline- & Registration of births or death. & 618 & 85.5 & 105 & 14.5 \\
\hline- & Making family medicine files. & 99 & 13.7 & 624 & 86.3 \\
\hline- & Others. eg (dental services) & 9 & 1.2 & 714 & 98.8 \\
\hline
\end{tabular}

Table 2: Declared that the majorities $(90.3 \%, 92.7 \%, 94.3 \%$, and 97\%) of the studied women was aware with health services provided by the family health centers such as follow - up of children, compulsory vaccinations for children, tetanus vaccinations for pregnant women, and antenatal care respectively. 


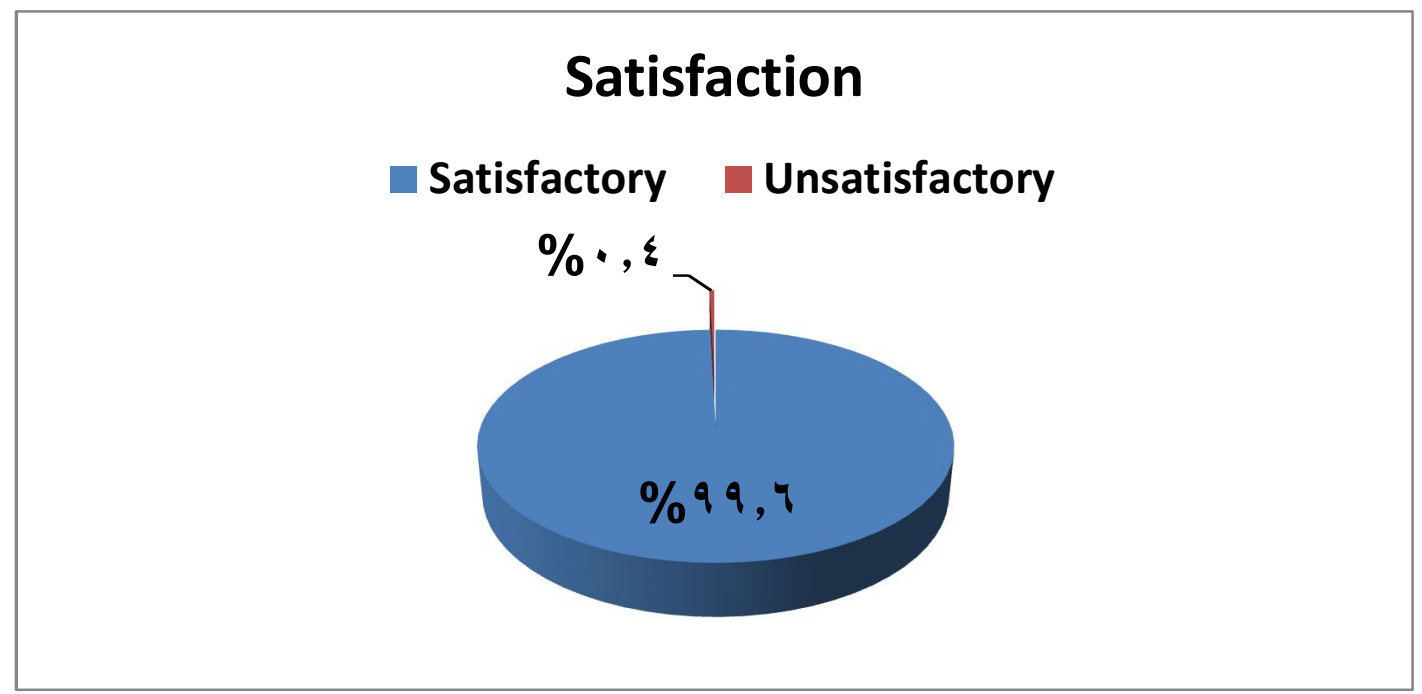

Figure (2) Total score of the studied women regarding their satisfaction about health services provided at the family health center $(n=723)$

Regarding the studied sample satisfaction of availability services provided at the family health center Figure (2) show that $99.6 \%$ are satisfy about health services.

Table 3: Pearson correlation between the studied women personal data, awareness and satisfaction with the health services provided at the family health center $(n=723)$

\begin{tabular}{|c|c|c|c|c|c|c|}
\hline Variable & 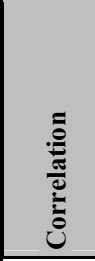 & 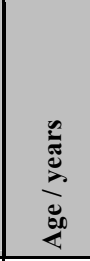 & 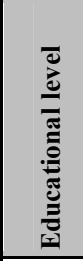 & 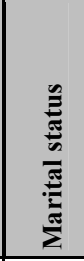 & 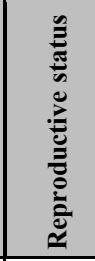 & 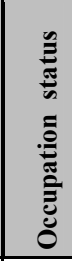 \\
\hline \multirow{2}{*}{ Awareness } & $\mathrm{r}$ & -0.077 & -0.087 & -0.061 & 0.109 & 0.010 \\
\hline & p-value & $0.039^{*}$ & $0.019^{*}$ & 0.102 & $0.003^{* *}$ & 0.790 \\
\hline \multirow{2}{*}{ Satisfaction } & $\mathrm{r}$ & 0.050 & -0.007 & -0.072 & 0.113 & 0.000 \\
\hline & p-value & 0.182 & 0.853 & 0.052 & $0.002^{* *}$ & 0.998 \\
\hline
\end{tabular}

Pearson correlation coefficient (r), P-value insignificant $P \geq 0.05, \quad *$ significant $P<0.05$, and **highly significant $P<0.01$

As regarding the Pearson correlation between the study sample personal data, awareness and satisfaction with the health services provided at the family health center Table (3)showed that there was weak positive correlation between the studied women reproductive status in relation to awareness and satisfaction $\mathrm{P}<0.01$. In addition, there were statistical weak negative correlation between age and educational level in relation to women awareness $\mathrm{P}<0.039 \& .019$ respectively.

Table 4: Relation between the studied women awareness and satisfaction with the health services provided at the family health center and the name of Family health center $(n=723)$

\begin{tabular}{|c|c|c|c|c|c|c|c|c|c|}
\hline \multirow{2}{*}{ Family health center } & \multicolumn{2}{|c|}{ Aware } & \multicolumn{2}{|c|}{ Not aware } & \multicolumn{2}{|c|}{ Satisfied } & \multicolumn{2}{|c|}{ Not satisfied } & \multirow{2}{*}{ P-value } \\
\hline & No. & $\%$ & No. & $\%$ & No. & $\%$ & No. & $\%$ & \\
\hline Menqbad & 70 & 18.9 & 133 & 37.8 & 138 & 30.9 & 65 & 23.5 & \multirow{5}{*}{$0.000 * *$} \\
\hline Dronka & 50 & 13.5 & 140 & 39.8 & 83 & 18.6 & 107 & 38.6 & \\
\hline Zawia & 213 & 57.4 & 47 & 13.4 & 163 & 36.5 & 97 & 35.0 & \\
\hline Bani Hussein & 38 & 10.2 & 32 & 9.1 & 62 & 13.9 & 8 & 2.9 & \\
\hline Total & 371 & 51.3 & 352 & 48.7 & 446 & 61.7 & 277 & 38.3 & \\
\hline
\end{tabular}

$\left(X^{2}\right)$ Chi-square test, $P$-value insignificant (NS) $\mathbf{P} \geq \mathbf{0 . 0 5}$, *significant $\mathbf{P}<\mathbf{0 . 0 5}$, and **highly significant $\mathbf{P}<\mathbf{0 . 0 1}$

Table 4: showed that $36.5 \%$ of satisfied women was from Zawia family health center followed by $30.9 \%$ of them was from Menqbad family health center while $38.6 \%$ of unsatisfied women was from Dronka family health centers with highly statistical significance differences which P- value $\leq 0.000$. 
Minia Scientific Nursing Journal (Print) (ISSN 2537-012X) Vol. (6) No. (1) December 2019

Table 5: Relation between studied women personal data and their awareness with the health services provided at the family health center $(\mathbf{n}=\mathbf{7 2 3})$

\begin{tabular}{|c|c|c|c|c|c|}
\hline \multirow{2}{*}{ Item } & \multicolumn{2}{|c|}{ Aware $(n=371)$} & \multicolumn{2}{|c|}{ Not aware $(n=352)$} & \multirow{2}{*}{ P-value } \\
\hline & No. & $\%$ & No. & $\%$ & \\
\hline \multicolumn{5}{|l|}{ Age / years } & \multirow{5}{*}{$0.0870 \mathrm{Ns}$} \\
\hline $18<30$ & 203 & 28.1 & 223 & 30.8 & \\
\hline $30<42$ & 132 & 18.3 & 99 & 13.7 & \\
\hline $42<54$ & 28 & 3.9 & 26 & 3.6 & \\
\hline 54 and more & 8 & 1.1 & 4 & 0.6 & \\
\hline \multicolumn{5}{|l|}{ Educational level } & \multirow{5}{*}{$0.071^{\mathrm{Ns} .}$} \\
\hline Illiterate & 124 & 17.2 & 128 & 17.7 & \\
\hline Basic education & 111 & 15.4 & 126 & 17.4 & \\
\hline Secondary & 78 & 10.8 & 60 & 8.3 & \\
\hline University education & 58 & 8.0 & 38 & 5.3 & \\
\hline \multicolumn{5}{|l|}{ Marital status } & \multirow{5}{*}{$0.273^{\mathrm{Ns}}$} \\
\hline Single & 21 & 2.9 & 25 & 3.5 & \\
\hline Married & 330 & 45.6 & 314 & 43.4 & \\
\hline Divorced & 12 & 1.7 & 11 & 1.5 & \\
\hline Widow & 8 & 1.1 & 2 & 0.3 & \\
\hline \multicolumn{5}{|l|}{ Occupation status } & \multirow{3}{*}{$0.790^{\mathrm{Ns}}$} \\
\hline Working & 25 & 3.5 & 22 & 3.0 & \\
\hline Housewife & 346 & 47.9 & 330 & 45.6 & \\
\hline \multicolumn{5}{|c|}{ Reproduction status for married participants } & \multirow{3}{*}{$0.000 * *$} \\
\hline Have children & 329 & 48.6 & 263 & 38.8 & \\
\hline Do not have children & 21 & 3.1 & 64 & 9.5 & \\
\hline
\end{tabular}

$\left(X^{2}\right)$ Chi-square test, $P$-value insignificant (NS) $P \geq 0.05$, * significant $P<0.05$, and **highly significant $P<0.01$

Table 5: Show that there is no significant relationship between study sample personal data and awareness with the health services provided at the family health center P-value $\geq 0.05$.

Table 6: Relation between studied women personal data and their satisfaction with the health services provided at the family health center $(n=723)$

\begin{tabular}{|c|c|c|c|c|c|}
\hline \multirow[t]{2}{*}{ Item } & \multicolumn{2}{|c|}{$\begin{array}{l}\text { Satisfied } \\
(\mathrm{n}=446)\end{array}$} & \multicolumn{2}{|c|}{$\begin{array}{l}\text { Unsatisfied } \\
(\mathrm{n}=277)\end{array}$} & \multirow{2}{*}{ P-value } \\
\hline & No. & $\%$ & No. & $\%$ & \\
\hline \multicolumn{5}{|l|}{ Age / years } & \multirow{5}{*}{$0.070^{\mathrm{Ns}}$} \\
\hline $18<30$ & 267 & 36.9 & 159 & 22.1 & \\
\hline $30<42$ & 142 & 19.6 & 89 & 12.3 & \\
\hline $42<54$ & 34 & 4.7 & 20 & 2.8 & \\
\hline 54 and more & 3 & 0.4 & 9 & 1.2 & \\
\hline \multicolumn{5}{|l|}{ Educational level } & \multirow{5}{*}{$0.665^{\mathrm{Ns} .}$} \\
\hline Illiterate & 154 & 21.3 & 98 & 13.6 & \\
\hline Basic education & 145 & 20.1 & 92 & 12.7 & \\
\hline Secondary & 91 & 12.6 & 47 & 6.5 & \\
\hline University education & 56 & 7.7 & 40 & 5.5 & \\
\hline \multicolumn{5}{|l|}{ Marital status } & \multirow{5}{*}{$0.007 * *$} \\
\hline Single & 18 & 2.4 & 28 & 3.9 & \\
\hline Married & 409 & 56.6 & 235 & 32.5 & \\
\hline Divorced & 12 & 1.7 & 11 & 1.5 & \\
\hline Widow & 7 & 1.0 & 3 & 0.4 & \\
\hline
\end{tabular}




\begin{tabular}{|c|c|c|c|c|c|}
\hline \multirow[t]{2}{*}{ Item } & \multicolumn{2}{|c|}{$\begin{array}{l}\text { Satisfied } \\
(\mathrm{n}=446)\end{array}$} & \multicolumn{2}{|c|}{$\begin{array}{l}\text { Unsatisfied } \\
(\mathrm{n}=277)\end{array}$} & \multirow[t]{2}{*}{ P-value } \\
\hline & No. & $\%$ & No. & $\%$ & \\
\hline \multicolumn{5}{|l|}{ Occupation status } & \multirow{3}{*}{$0.998^{\mathrm{Ns} .}$} \\
\hline Working & 29 & 4.0 & 18 & 2.5 & \\
\hline Housewife & 417 & 57.7 & 259 & 35.8 & \\
\hline \multicolumn{5}{|c|}{ Reproduction status for married participants } & \multirow{3}{*}{$0.005^{* *}$} \\
\hline Have children & 375 & 55.4 & 217 & 32.1 & \\
\hline Do not have children & 53 & 7.8 & 32 & 4.7 & \\
\hline
\end{tabular}

\section{$\left(\mathrm{X}^{2}\right)$ Chi-square test, $\mathrm{P}$-value insignificant (NS) $\mathrm{P} \geq \mathbf{0 . 0 5}$, *significant $\mathrm{P}<0.05$, and **highly significant $\mathrm{P}<0.01$}

Regarding the relation between study sample personal data and satisfaction with the health services provided at the family health center Table 6 show that there wasn't significant relationship between study sample personal data and satisfaction with the health services provided at the family health center $\mathrm{P}$-value $\geq 0.05$

\section{Discussion}

Health services are of paramount importance to improving women's and children's health and women's satisfaction with the services provided in family health centers, it is important to assess women satisfaction with care in order to make it more responsive and culturally acceptable, ultimately leading to enhanced utilization and improved outcomes (Sayed et al., 2018).

\section{The socio demographic characteristics of the studied women:}

It revealed that more than half of the studied women were in age group 18- $<30$ years, while the least percentage was in the age group 54 and more years with age mean and standard deviation $29.8 \pm 8.48$ year. This in the same line with Wereta et al., (2018) who found the mean age of women who seeks for medical care were around 25 years old which consider the age of reproduction.

The same characteristics was reported by Dodson et al., (2016) in the study about Sense of mission and sexual health outcomes among young adult women suggested that young women with ages ranged between 15 -35 had more regular attendance to family health center than older women.

As regard the level of education, more than one third of the studied women were illiterate, and the minority of them had university education. This result in the same line with Brugiavini, \& Pace, (2016) studied extending health insurance in Ghana entitled "effects of the National Health Insurance Scheme on maternity care" confirmed that educated women are more likely to receive care in the health centers than low and non-educated women.

This result contradicted with Badal et al., (2018) studied "knowledge and support, women can attend antenatal care, in Somaliland", found that most of studied women were read and write.

Regarding occupation status the highest percentage was housewife while the lowest percentage of the studied women was working. This result agreed with Khatun et al., (2018) in the study about "The relationships among postpartum fatigue, depressive mood, self-care agency, and self-care action of first-time mothers" in Bangladesh reported that majority of the women were housewives.

Regarding number of children for studied women who attended in family health centers found that more than one third of studied women had 3 to 4 children and less than one third of them had one to two children. This result

$P$ a g e | 164 compatible with Jukes et al., (2008) who mentioned that: In Egypt, early marriage and poverty are factors responsible for lower education of girls; therefore, there is an urgent need to focus on the need for higher education in health programs but disagreed with Khatun et al., (2018) reported that more than one third had first births to less than quarter for sixth or higher order births.

The present study showed that more than half of studied women aware about this health services. This finding in the same line with Seçkin et al., (2016) in a study about being an informed consumer of health information and assessment of electronic health literacy in a national sample of internet users identified a low awareness by the respondents of specific health and medical information resources.

Additionally, the result of this study declares that the majority of the studied women was aware with health services provided by the family health centers such as follow - up of children, compulsory vaccinations for children, tetanus vaccinations for pregnant women, and antenatal care respectively. This compatible with Siu, (2015) in the study about "Behavioral and pharmacotherapy interventions for tobacco smoking cessation in adults, including pregnant women" found that the main services which women focus on to be received at the health care centers was pregnant women follow up.

Generally, more than half of the studied women were satisfied about health services. In this respect Liberati, et al., (2009) in the study about The PRISMA statement for reporting systematic reviews and meta-analyses of studies that evaluate health care interventions founded that, most studies reported maternal satisfaction in terms of the proportion of women expressing satisfaction with maternal care. Ratings of maternal satisfaction indicate generally high ratings across developing countries. Also, this result agreed with Kaner et al., (2018) studied "Effectiveness of brief alcohol interventions in primary care populations found that, more than three quarters of the women reported care to be satisfactory

In addition, the present study showed that there was significance relationship between the studied woman awareness with the health services provided at the family health center and the different of family health centers. In this respect the study of Shorter, (2017) about women's bodies: a social history of women's encounter with health, ill-health and medicine found there was a significant difference between health centers in different places this may related to the

Hala R., et al 
changes in the women characters (believes, customs and other factors) of each from other places.

Also, the present study reveled that there is no significant relationship between studied woman personal data and awareness with the health services provided at the family health center $P$-value $\geq 0.05$. It noticed that certain factors seemed to affect woman awareness except reproduction status for married participants. Age seemed to affect knowledge so the high age woman had adequate knowledge than young age group. This is expected younger women usually limited experience and this may influence their information and knowledge. The current study was differ from result of which reported that women's age effect on the level of their awareness.

In this concern, the exciting research found that there was no statistically significant relationship between demographic data of the studied women and their satisfaction with the health services provided at the family health centers except between their marital status in which $91.7 \%$ of satisfied women was married vs $84.8 \%$ of unsatisfied women. These results agreed with Srivastava et al., (2015) in the study about determination of women's satisfaction with maternal health care: a review of literature from developing countries revealed that; determinants of maternal satisfaction covered all dimensions of care across structure, process and outcome. Structural elements includes good physical environment, cleanliness, and availability of adequate resources, medicines and supplies. Process determinants included interpersonal behavior, privacy, promptness, cognitive care, perceived and supplies.

\section{Conclusion}

There was fair level of awareness about health services provided at family health centers and satisfaction among the majority of the women. The Family Health Model has achieved successes when implemented but encountered some difficulties that have limited the gains and interfered with some of its aspects. The current study has shown that the Family Health centers has gained a high score of satisfaction and acceptability by the study participants.

\section{Recommendations:}

- Improve the efficiency and effectiveness of health services provided in family health center.

- Women satisfaction survey should be carried out routinely to improve the quality of services.

- Ensure the availability of all health services in the family health center.

- Health services providers require training to strengthen their communication skills so that they can meet their client's individual needs.

- Health education programs on how to improve health promotion, vaccinations, periodic screening and environmental improvement.

\section{Reference}

1) Adhikari, R., Soonthorndhada, K., \& Prasartkul, P. (2009). Correlates of unintended pregnancy among currently pregnant married women in Nepal. BMC International Health and Human Rights, 9(1), 17.

2) Badal, N. F., Yusuf, U. A., Egal, J., Pedersen, C., Erlandsson, K., Osman, F., \& Byrskog, U. (2018). With knowledge and support, women can attend antenatal care: The views of women in IDP camps in
Somaliland. African Journal of Midwifery and Women's Health, 12(3), 138-143.

3) Brault, M. A., Ngure, K., Haley, C. A., Kabaka, S., Sergon, K., Desta, T., ... \& Kipp, A. M. (2017). The introduction of new policies and strategies to reduce inequities and improve child health in Kenya: A country case study on progress in child survival, 2000-2013. PloS one, 12(8), e0181777

4) Brugiavini, A., \& Pace, N. (2016). Extending health insurance in Ghana: effects of the National Health Insurance Scheme on maternity care. Health economics review, 6(1), 7.

5) Coast, E., Jones, E., Portela, A., \& Lattof, S. R. (2014). Maternity care services and culture: a systematic global mapping of interventions. PloS one, 9(9), e108130.

6) Dodson, N. A., Corliss, H. L., Sarda, V., Emans, S. J., \& Field, A. E. (2016). Sense of mission and sexual health outcomes among young adult women. Journal of pediatric and adolescent gynecology, 29(6), 567-570.

7) Dyer, T., Owens, J., \& Robinson, P. G. (2016). The acceptability of healthcare: from satisfaction to trust. Community dental health, 33, 1-10.

8) Laiteerapong, N., Kirby, J., Gao, Y., Yu, T. C., Sharma, R., Nocon, R., ... \& Huang, E. S. (2014). Health care utilization and receipt of preventive care for patients seen at federally funded health centers compared to other sites of primary care. Health services research, 49(5), 1498-1518.

9) Ebeid, Y. (2016). The acceptability of the Family Health Model, that replaces Primary Health Care, as currently implemented in Wardan Village, Giza, Egypt..(1),1- 28.

10) Jallow, I. K., Chou, Y. J., Liu, T. L., \& Huang, N. (2012). Women's perception of antenatal care services in public and private clinics in the Gambia. International journal for quality in health care, 24(6), 595-600.

11) Khatun, F., Lee, T. W., Rani, E., Biswash, G., Raha, P., \& Kim, S. (2018). The relationships among postpartum fatigue, depressive mood, selfcare agency, and self-care action of first-time mothers in Bangladesh. Korean Journal of Women Health Nursing, 24(1), 49-57.

12) Kotzias, V., Engel, C. C., Ramchand, R., Ayer, L., Predmore, Z., Ebener, P., ... \& Karras, E. (2019). Mental health service preferences and utilization among women veterans in crisis: perspectives of veterans crisis line responders. The journal of behavioral health services \& research, 46(1), 29-42.

13) Kuo, D. Z., Houtrow, A. J., Arango, P., Kuhlthau, K. A., Simmons, J. M., \& Neff, J. M. (2012). Family-centered care: current applications and future directions in pediatric health care. Maternal and child health journal, 16(2), 297-305.

14) Marsland, H., Meza, G., de Wildt, G., \& Jones, L. (2019). A qualitative exploration of women's experiences of antenatal and intrapartum care: The need for a woman-centred approach in the Peruvian Amazon. PloS one, 14(1), e0209736.

15) Neuhausen, K., Grumbach, K., Bazemore, A., \& Phillips, R. L. (2012). Integrating community health centers into organized delivery systems can improve 
access to subspecialty care. Health Affairs, 31(8), 1708-1716.

16) Nocon, R. S., Lee, S. M., Sharma, R., NgoMetzger, Q., Mukamel, D. B., Gao, Y., ... \& Huang, E. S. (2016). Health care use and spending for Medicaid enrollees in federally qualified health centers versus other primary care settings. American journal of public health, 106(11), 1981-1989.

17) Sayed, S. H., Elgzar, W. T. I., \& Ibrahim, H. A. F. (2018). Quality of Family Planning Services in Maternal and Child Health Care Centers in Damanhour City. International Journal of Studies in Nursing, 3(2), 88.

18) Seçkin, G., Yeatts, D., Hughes, S., Hudson, C., \& Bell, V. (2016). Being an informed consumer of health information and assessment of electronic health literacy in a national sample of internet users: validity and reliability of the e-HLS instrument. Journal of medical Internet research, 18(7), e161.

19) Shorter, E. (2017). Women's bodies: a social history of women's encounter with health, ill-health and medicine. Routledge.p.P 357.

20) Siu, A. L. (2015). Behavioral and pharmacotherapy interventions for tobacco smoking cessation in adults, including pregnant women: US Preventive Services Task Force recommendation statement. Annals of internal medicine, 163(8), 622-634

21) Srivastava, A., Avan, B. I., Rajbangshi, P., \& Bhattacharyya, S. (2015). Determinants of women's satisfaction with maternal health care: a review of literature from developing countries. BMC pregnancy and childbirth, 15(1), 97.

22) Ten Hoope-Bender, P., de Bernis, L., Campbell, J., Downe, S., Fauveau, V., Fogstad, H., ... \&
Renfrew, M. J. (2014). Improvement of maternal and newborn health through midwifery. The Lancet, 384(9949), 1226-1235.

23) Wereta, T., Betemariam, W., Karim, A. M., Zemichael, N. F., Dagnew, S., Wanboru, A., \& Bhattacharya, A. (2018). Effects of a participatory community quality improvement strategy on improving household and provider health care behaviors and practices: a propensity score analysis. BMC pregnancy and childbirth, 18(1), 364.

24) Wood, S., Beeson, T., Bruen, B., Goldberg, D. G., Mead, H., Shin, P., \& Rosenbaum, S. (2014). Scope of family planning services available in federally qualified health centers. Contraception, 89(2), 85-90.

25) Wood, S., Goldberg, D. G., Beeson, T., Bruen, B. K., Johnson, K., Mead, H., ... \& Cunningham, M. (2013). Health Centers and Family Planning: Results of a Nationwide Study.

26) World Health Organization. (2017). Enhancing the role of community health nursing for universal health coverage. (8), 1-32.

27) Radhi, M. M. (2016). Evaluation of Consumers' Satisfaction towards Rural Primary Health Care Services in Babylon Governorate. International Journal of Scientific and Research Publications, (6) 6,548 .

28) Mohamed, E. Y., Sami, W., Alotaibi, A., Alfarag, A., Almutairi, A., \& Alanzi, F. (2015). Patients' satisfaction with primary health care Centers' Services, Majmaah, kingdom of Saudi of Saudi Arabia. International journal of health sciences, 9(2), 163 